\title{
Estratégias pedagógicas, planejamento e construção de Objetos de Aprendizagem para uso pedagógico
}

Mary Lúcia Pedroso Konrath, Pedagoga, Especialista em Informática na Educação, Mestre em Educação e Doutoranda do Programa de Pós-Graduação em Informática na Educação PPGIE/UFRGS, marykonrath@globo.com

Mara Lúcia Fernandes Carneiro, Doutora em Informática na Educação - PPGIE/UFRGS e Professora do Instituto de Psicologia da UFRGS, mara.carneiro@ufrgs.br

Liane Margarida R. Tarouco, Mestre em Ciência da Computação e Doutora em Engenharia Elétrica-Sistemas Digitais e Professora do Programa de Pós-Graduação em Informática na Educação - PPGIE/UFRGS, liane@ penta.ufrgs.br

Resumo. Este artigo descreve como a perspectiva teórica que fundamenta os objetos de aprendizagem, influencia diretamente as estratégias pedagógicas, planejamento e uso de um objeto de aprendizagem na prática pedagógica. Os resultados apresentados são fruto de uma pesquisa de Mestrado, do Programa de pós-graduação em Educação na linha de pesquisa Informática na Educação da Universidade Federal do Rio Grande do Sul. Através desta buscava-se inventariar quais estratégias pedagógicas são planejadas e usadas por professores no uso do objeto de aprendizagem "Nós no mundo". Foram analisados estratégias descritas nos planejamentos por professores do curso de extensão Oficina de Formação de Professores, realizado pelas pesquisadoras no Centro Interdisciplinar de Novas Tecnologias na Educação.

Palavras-chave: planejamento, perspectiva teórica, objetos de aprendizagem

\section{Teaching strategies, plannig and learning objetcs construction for pedagogical use}

\begin{abstract}
This paper describes how the theoretical perspective that suports the learning objects, influences directly the teaching strategies, planning and use of an learning object in pratice pedagogical. The results presented are the result of a search for Master of Post-graduate Program in Education at the line of research in Computer Science Education, Federal University of Rio Grande do Sul. Through this survey which is seeking teaching strategies are planned and used by teachers in the use of the learning object "Nós no mundo". We analyzed strategies described by teachers in planning the course of extension of Teacher Training Workshop, conducted by researchers at the Interdisciplinary Center of New Technologies in Education.
\end{abstract}

Keywords: planning, theoretical, learning objects.

\section{Introdução}

A partir do avanço tecnológico e suas transformações na sociedade, educação, cultura, comunicação e lazer tem se buscado cada vez mais aprofundar os estudos e recursos a serem disponibilizados na Educação, sejam eles para a modalidade presencial ou a distância.

A tecnologia pode provocar profundas transformações na realidade social e educacional, desde que ela seja utilizada de forma adequada e condizente com a perspectiva teórica que embasa o trabalho pedagógico do professor. O problema é que embora tenhamos avançado em termos de perspectivas teóricas e pensemos que o conhecimento deve ser 
construído e não mais transmitido, os recursos didáticos e em especial, objetos de aprendizagem em sua grande maioria não acompanham essa mudança.

A maioria dos objetos de aprendizagem, comumente produzidos, ainda seguem uma perspectiva teórica que o fundamenta a partir de uma perspectiva mais tradicional, calcada na apresentação de conhecimentos e informações.

Este artigo mostra como a perspectiva teórica que fundamenta os objetos de aprendizagem, influenciam diretamente as estratégias pedagógicas, planejamento e uso dos objetos de aprendizagem na prática pedagógica.

Neste espaço, apresentamos ao leitor, em primeiro lugar, definição do conceito objetos de aprendizagem e algumas perspectivas teóricas que sustentam a sua construção. A seguir, o objeto de aprendizagem "Nós no mundo" e sua fundamentação teórica. Depois, descrevemos o curso de extensão Oficina de Formação de Professores e o que entendemos sobre estratégias pedagógicas e planejamento e como elas se apresentaram quando professores da oficina planejaram o uso do objeto de aprendizagem "Nós no mundo".

\section{Objetos de aprendizagem e perspectivas teóricas}

Objetos de aprendizagem são "qualquer entidade, digital ou não, que pode ser utilizada, reutilizada ou referenciada durante o processo de aprendizagem que utilize tecnologia" (IEEE, 2000).

Entende-se objetos de aprendizagem como qualquer material ou recurso digital com fins educacionais, ou seja, recursos que podem ser utilizados no contexto educacional de maneiras variadas e por diferentes sujeitos. Essa definição, mais específica, baseia-se em Sosteric e Hesemeier (2001), que consideram como objetos de aprendizagem desde imagens e gráficos, vídeos, sons, ferramentas até qualquer outro recurso educacional digital a ser utilizado para fins educacionais e que contenham sugestões sobre o contexto de sua utilização.

Os objetos de aprendizagem podem ser utilizados tanto para apoiar o processo de ensino-aprendizagem presencial ou à distância. $\mathrm{O}$ mais importante é saber onde encontrar ${ }^{1}$ e selecionar os objetos de aprendizagem, buscando aqueles que sejam adequados à proposta pedagógica do professor e que contribua para a aprendizagem dos alunos com os quais se está desenvolvendo o trabalho pedagógico.

Os objetos de aprendizagem são construídos a partir de uma perspectiva teórica e podem ser desde animações simples para apresentação/demonstração de um determinado conhecimento até um objeto mais complexo centrado na interação entre os alunos e professor, como o caso do objeto de aprendizagem "Nós no mundo".

Entre as concepções teóricas, apresentamos aqui três perspectivas pedagógicas dominantes: associacionista, cognitiva e situada. (LITO e FORMIGA, 2009)

\footnotetext{
${ }^{1}$ Existem hoje repositórios de objetos de aprendizagem, com objetos de aprendizagem de diversas áreas catalogados tanto no exterior como no Brasil. Como exemplos de repositórios de aprendizagem temos: MERLOT, LABVIRT, RIVED e CESTA.
} 
(1) A perspectiva associacionista é a concepção "[...] que considera a aprendizagem como mudança de comportamento [...] observáveis e mensuráveis do comportamento, decorrentes de respostas a estímulos externos". (LITO e FORMIGA, 2009, p. 96-97)

Nesta teoria (LITO e FORMIGA, 2009, p. 99) afirmam que

“[...] as pessoas aprendem por associação, inicialmente por condicionamento estímulo/resposta simples, posteriormente através da capacidade de associar conceitos em uma cadeia de raciocínio, ou de associar passos em uma cadeia de atividades para construir uma habilidade complexa".

Neste sentido, o comportamento é um indicador do que foi aprendido. Tem como principais teóricos Skinner e Gagné. Tem como exemplos a instrução guiada e o exercício e prática. A concepção empirista se enquadra neste espaço, encarando o conhecimento como fonte externa ao sujeito, trazido pelo professor ou recurso que contenha a apresentação de informações.

(2) A perspectiva cognitiva é a concepção “[...] que vê a aprendizagem como alcance da compreensão [...] processos internos de percepeção, representação, armazenamento e recuperação de conhecimentos". (LITO e FORMIGA, 2009, p. 96-97)

Nesta perspectiva é que se enquadram as concepções construtivistas e socioconstrutivistas nas quais o conhecimento é construído a partir da interação do sujeito com o objeto de conhecimento e com base em experiências próprias do mesmo. Tem com principais teóricos Piaget (individual) e Vigotsky (social).

Nesta teoria sob o enfoque construtivista (LITO e FORMIGA, 2009, p. 99) afirmam que

“[...] as pessoas aprendem ao explorar ativamente o mundo que as rodeia, recebendo feedback sobre suas ações e formulando conclusões. A capacidade de construir leva a integração de conceitos e habilidades dentro das estruturas de competências ou de conceitos já existentes no aluno".

Já para o enfoque socioconstrutivista

"[...] a descoberta individual de princípios é intensamente suportada pelo ambiente social. Os colegas de estudo e os professores desempenham um papel fundamental no desenvolvimento, ao participarem do diálogo com o aluno, ao desenvolverem uma compreensão compartilhada da tarefa e ao fornecerem feedback das atividades e as representações do aluno". (LITO e FORMIGA, 2009, p. 99)

Enquanto no primeiro enfoque a aprendizagem é vista como a construção ativa e integração de conceitos o segundo vê como o desenvolvimento conceitual por meio de atividades colaborativas.

(3) perspectiva situada é a concepção “[...] que entende a aprendizagem como prática social [...] conhecimento localizado na ação de pessoas e grupos [...]". (LITO E FORMIGA, 2009, p. 96 e p. 98) 
Nesta teoria (LITO e FORMIGA, 2009, p. 99) afirmam que

[...] as pessoas aprendem ao participar de comunidades de prática, progredindo da posição de novatos até a de especialistas através da observação, reflexão, mentoria e "legítima participação periférica". Da mesma maneira que o socioconstrutivismo, a abordagem situada enfatiza o contexto social da aprendizagem, mas este contexto deve ser muito mais próximo - ou idêntico - à situação na qual o aluno eventualmente aplicará a aprendizagem adquirida.

Esta concepção tem como principais teóricos Lave e Wenger, Cole, Engstrom e Wertsch. A interação social e a colaboração são componentes essenciais para a aprendizagem.

A perspectiva teórica é quem dá pistas principalmente de como será o conteúdo e as interações de um objeto de aprendizagem. Desta forma é tão importante antes de projetar um recurso educacional pensar a partir de que concepção será produzido.

\section{O objeto de aprendizagem "Nós no mundo" e sua perspectiva teórica}

O objeto de aprendizagem "Nós no mundo" ${ }^{2}$ foi produzido por uma equipe de pesquisadores das áreas de Educação, Informática e Informática na Educação dos programas de Pós-Graduação em Educação e Informática na Educação da Universidade Federal do Rio Grande do Sul. A equipe foi desafiada a desenvolver um objeto de aprendizagem que pudesse ser utilizado com alunos das Séries Iniciais do Ensino Fundamental. O objeto teve presente, desde sua concepção, paradigmas construtivistas, que levassem em conta a interação entre os alunos.

A mediação pedagógica é a perspectiva que embasou a construção deste objeto e a partir dela que todos os processos de planejamento, desenvolvimento e implementação foram projetados.

Diante deste desafio, o grupo manifestou-se pela produção de algo diferenciado em relação aos materiais digitais disponíveis. Esses, em sua maioria, são de caráter tradicional, nos quais são oferecidas atividades que demandam respostas predeterminadas e sua natureza carrega, como concepção, a aprendizagem por estímulo e resposta. Nosso objetivo era produzir algo que pudesse motivar os alunos a buscar, a compartilhar suas descobertas e a aprender com elas juntamente com os demais colegas, apoiados e desafiados pelo professor, entendido aqui como mediador dessa aprendizagem.

Na construção deste objeto, trabalhamos com o tema transversal - Pluralidade Cultural que oportuniza um olhar interdisciplinar, envolvendo não somente um conteúdo específico.

Como inspiração do grupo e possível apoio para as propostas didáticas que o professor possa criar, apresenta-se um conjunto de fragmentos retirados dos $\mathrm{PCNs}^{3}$ e estes fragmentos foram dispostos junto com o guia do professor no próprio objeto.

\footnotetext{
${ }^{2}$ Disponível em http://pead.faced.ufrgs.br/objetos/nosnomundo2, para acessar é preciso ser cadastrado como professor ou aluno.

${ }^{3}$ PCNS - Parâmetros Curriculares Nacionais, materiais elaborados pelo Governo Federal que trazem referências de qualidade para o Ensino Fundamental e Médio do país.
} 
"Nós no mundo"4 reúne um conjunto inicial de atividades, comentadas na seqüência, que possibilitam ao professor trabalhar, de forma geral com a Pluralidade Cultural e, de forma específica, com componentes curriculares de Língua Portuguesa, Matemática, História e Geografia. Ele foi criado para ser utilizado na prática pedagógica com crianças alfabetizadas ou em processo de alfabetização, tendo em vista que trabalha predominantemente com a interação via linguagem textual. Para facilitar a interação dos sujeitos envolvidos, o sistema permite que as interações ocorram apenas entre os alunos de uma mesma turma. Assim, ele busca oferecer espaços para que o aluno possa expressar-se e aprender.

A partir do objeto de aprendizagem "Nós no mundo" foi então que pensamos em propor através do curso de extensão Oficina de Formação de Professores que profissionais da área de educação, ou seja, professores pudessem vivenciar uma formação através de uma proposta diferenciada condizente com a perspectiva teórica do objeto de aprendizagem o que será detalhado no próximo item deste artigo.

\section{Curso de extensão Oficina de Formação de Professores}

O curso de extensão Oficina de Formação de Professores foi planejado como forma de capacitar recursos humanos para a avaliação, planejamento e uso de recursos digitais na Educação.

Nele foram trabalhados os aspectos tecnológicos destes recursos e suas potencialidades pedagógicas. A carga horária total do curso de extensão foi de 40 horas, sendo 18 horas presenciais e 22 horas de interação via ambiente de aprendizagem virtual TelEduc.

Os encontros presenciais foram na forma de oficina de formação no laboratório de Informática do Centro Interdisciplinar de Novas Tecnologias na Educação, equipado com 22 computadores, projetor multimídia e microfone para gravação de alguns dos encontros. No curso preencheram o formulário de inscrição on-line 17 professores, porém somente 11 professores efetivaram sua inscrição.

O curso teve como objetivo geral a capacitação de docentes das redes pública e privada para a avaliação, uso e planejamento de recursos digitais na Educação, dentre eles: explorar, avaliar e planejar o uso do objeto de aprendizagem "Nós no mundo" no contexto de sala de aula com seus alunos.

Como objetivos específicos o curso buscava: (1) conhecer e explorar recursos digitais (portais educacionais, softwares e jogos educacionais, objetos de aprendizagem, repositórios de objetos de aprendizagem, revistas eletrônicas e artigos relacionados ao tema) e conceitos básicos relacionados a este tipo de material educacional; (2) capacitar os professores a buscar objetos de aprendizagem nos repositórios, avaliar e planejar seu

\footnotetext{
${ }^{4}$ Para saber mais detalhes sobre o objeto de aprendizagem "Nós no mundo" acessar artigos Explorando estratégias pedagógicas através de "Nós no mundo" v.4, nº 2, Dezembro, 2006 e "Nós no Mundo": Objeto de Aprendizagem voltado para o $1^{\circ}$ Ciclo do Ensino Fundamental v. 4 $\mathrm{n}^{\mathrm{o}}$ 1, Julho, 2006, publicados na Revista de Novas Tecnologias na Educação, disponível em http://www.cinted.ufrgs.br/renote.
} 
uso e (3) refletir sobre a importância da inclusão digital dos professores no atual contexto.

O curso teve 5 encontros presenciais conforme programação a seguir:

\begin{tabular}{|l|l|}
\hline \multicolumn{1}{|c|}{ Aulas presenciais } & \multicolumn{1}{|c|}{ Programação do curso de extensão } \\
\hline $1^{\mathrm{a}}$. Aula-18/10/2006 & $\begin{array}{l}\text { Recursos digitais e Objetos de aprendizagem } \\
\text { - Apresentação do ambiente virtual de aprendizagem TelEduc } \\
\text { que será utilizado no curso e cadastramento dos alunos }\end{array}$ \\
$\begin{array}{l}\text { - Exploração de repositórios e objetos de aprendizagem } \\
\text { - Registro sobre a experiência de exploração dos objetos que será } \\
\text { realizado no TelEduc }\end{array}$ \\
\hline $2^{\text {a Aula-25/10/2006 }}$ & $\begin{array}{l}\text { "Nós no mundo" } \\
\text { - Exploração do objeto de aprendizagem "Nós no mundo" }\end{array}$ \\
\hline $3^{\text {a Aula }-08 / 11 / 2006}$ & Práticas pedagógicas e planejamento didático-pedagógico \\
\hline $4^{\mathrm{a}}$ Aula $-29 / 11 / 2006$ & Planejamento didático-pedagógico \\
\hline $5^{\mathrm{a}}$ Aula-13/12/2006 & Compartilhando experiências \\
\hline
\end{tabular}

O curso de extensão teve dinâmica diferenciada, pois envolveu momentos de exploração e discussão dos temas - ao invés da apresentação dos conceitos de objetos de aprendizagem - exemplos de objetos produzidos, visitas a repositórios de Objetos de Aprendizagem disponíveis na Internet, exploração de jogos e portais educacionais disponíveis na rede. Durante o curso, os participantes conheceram, exploraram, planejaram e apresentaram seus planejamentos para o grupo sobre o objeto "Nós no mundo".

Durante os momentos presenciais, observamos e registramos a exploração do objeto e mediamos as discussões, acompanhando as impressões dos professores sobre os temas trabalhados, principalmente sobre a questão do planejamento.

No primeiro encontro com o grupo, realizamos uma dinâmica de grupo para que todos se conhecessem. Todos fizeram o cadastro e propomos a familiarização dos alunos com o ambiente virtual utilizado no curso.

$\mathrm{Na}$ segunda aula propomos a exploração de alguns repositórios e objetos de aprendizagem, produzidos em âmbito nacional e pelos pesquisadores da Universidade Federal do Rio Grande do Sul.

$\mathrm{Na}$ terceira aula, após um debate sobre questões referentes às abordagens pedagógicas, cada participante recebeu um instrumento para registrar seu planejamento de uso didático-pedagógico do objeto, porém alguns fizeram seu planejamento em duplas ou trios. Após sua realização anexaram-no em seu portfólio no ambiente de aprendizagem utilizado para o curso.

No penúltimo e último encontro do curso, os alunos apresentaram os seus planejamentos e foram avaliados por uma banca composta pelos próprios cursistas. Realizamos um debate sobre planejamento e os temas que apareceram durante as apresentações, questionamentos e discussões, sendo gravadas as interlocuções e, posteriormente, degravadas. A degravação dos encontros foi também utilizada como dado da pesquisa, juntamente com os planejamentos entregues por escrito. Neste último encontro os participantes realizaram individualmente a avaliação do curso. 
No curso de extensão utilizamos um questionário sobre contexto de utilização de ferramentas e recursos digitais na educação para conhecer os alunos, seu trabalho e carga horária, assim como sua familiaridade com os recursos tecnológicos apresentados e um Instrumento de planejamento didático-pedagógico para o uso do objeto de aprendizagem "Nós no mundo".

Para a análise dos dados do curso de extensão foram considerados todos os professores que estiveram presentes no curso e que entregaram seu planejamento didáticopedagógico. A análise foi realizada sobre: 5 planejamentos realizados por 8 professores, 3 depoimentos e a degravação do vídeo de apresentação dos planejamentos apresentados.

Como procedimento de análise utilizamos a Análise de Conteúdo proposta por Ramos (1999). O autor compreende a Análise de Conteúdo como uma das metodologias de análise de texto que, devido à simplicidade com que trata as informações, é, muitas vezes, sugerida para estudos qualitativos de depoimentos e entrevistas.

\begin{abstract}
A análise de conteúdo é um processo de busca de compreensão da realidade, que ocorre através da interpretação de textos que tenham vínculos com esta realidade. Portanto, este tipo de análise revela-se uma possibilidade de extrairmos o conteúdo, tanto o explícito como o latente, de textos geralmente escritos. Os procedimentos empregados para a análise de conteúdo dependem dos objetivos do estudo, do material que temos para o trabalho e do contexto do qual foram extraídos os textos. Em geral, acontecem em três momentos: a organização do material ou do corpus que será alvo de estudo, análise do material, com destaque para a identificação de unidades de significado e para as categorizações e organização de textos descritivos e, finalmente, a interpretação. (RAMOS, p.5, 1999)
\end{abstract}

Os procedimentos que foram empregados para a análise de conteúdo foram adaptados aos objetivos do estudo, do material e do contexto do qual foram extraídos os dados para a análise. Os procedimentos utilizados foram: (a) organização do material alvo de estudo, (b) análise do material e (c) interpretação. (Ramos, 1999)

A pesquisa buscava inventariar quais estratégias pedagógicas são planejadas e usadas por professores no uso do objeto de aprendizagem "Nós no mundo" e alguns dos resultados serão apresentados no capítulo seguinte deste artigo.

\title{
5. Estratégias pedagógicas e planejamento a partir de "Nós no mundo"
}

O planejamento educacional diz respeito ao plano que orienta as decisões do professor, de sua concepção de educação, aprendizagem, da forma de planejar e no conhecimento que deve ser trabalhado.

Através deste é preciso estabelecer objetivos educacionais do tema a ser tratado, as estratégias educacionais e atividades de avaliação, representando as responsabilidades do professor e seus objetivos de forma clara e mais completa possível. Manata confirma a importância das estratégias considerando que "o processo de planejamento visa promover a mudança nas estratégias docentes da prática pedagógica cotidiana” (2004, p. $8)$.

O planejamento deve ser feito a partir de referências na busca de intencionalidades, percebendo que a ação pedagógica deve estar sustentada por pressupostos teóricos, os quais segundo Rodrigues (2002, p.17) "estabelecem as diretrizes do trabalho, definindo 
procedimentos e estratégias metodológicas. [... ] planejar é a constante busca de aliar o "para que" ao "como" [...]"

A partir de leituras sobre planejamento, foi possível observar que o planejamento educacional segue uma orientação pedagógica e que há diferentes linhas que orientam as formas de organizar o planejamento.

Desta forma, as análises foram agrupadas em 5 categorias, extraídas dos próprios planejamentos: 1) abordagem pedagógica, 2) orientação metodológica do trabalho, 3) função do professor, 4) técnicas e 5) conteúdos.

A categoria abordagem pedagógica permitiu identificar a concepção teórica do planejamento e das estratégias apresentadas pelo mesmo.

A orientação metodológica do trabalho foi dividida em duas orientações diferenciadas. A primeira foi chamada de "elementar" pois trabalha a partir de uma temática e possui elementos básicos como: conteúdos, estratégias, localização, recursos e avaliação, correlacionando o "para quê" ao "como".(RODRIGUES, 2003) A segunda tem se a proposta da metodologia de projetos na educação, que propõe a ação do sujeito a partir de uma problematização, na busca de informações (conteúdos) que pode vir a acessar através da inter-relação com o meio, representado por fontes como a natureza, a tecnologia, o professor e outros sujeitos. Os projetos podem ser desdobrados em: "projetos de ensino", propostos por professores e coordenadores a partir de critérios formais, sendo os alunos convidados a participarem na medida que tem espaço para expor, debater suas opiniões sobre o tema e questões definidas no projeto.

A categoria relacionada a função do professor buscava analisar o papel que o professor assume diante de seu trabalho, estruturando a metodologia de aprendizagem utilizada em sua prática, assim como sua relação com os atores que fazem parte deste contexto. Foram identificadas as seguintes sub-categorias: o professor "mediador" e o professor "especialista". O professor mediador refere-se aquele que possui conhecimentos e ou experiências a comunicar indiretamente para seus alunos, mediando e orientando as atividades de forma a facilitar a construção de conhecimento pelo grupo de alunos. Já o papel de professor especialista refere-se aquele que possui conhecimentos e ou experiências a comunicar para seus alunos e o faz por meio da transmissão de conhecimentos, entendendo o ensino como um processo natural, no qual basta o aluno entrar em contato com determinado conteúdo para aprendê-lo.

A categoria relacionada as técnicas refere-se as ações escolhidas ou criadas pelo professor, para colocar em prática suas estratégias pedagógicas. E por fim os conteúdos são entendidos como os "saberes", conhecimentos da realidade sistematizados de forma a poderem ser trabalhados através da prática pedagógica escolar. Os conteúdos podem ser trabalhados de duas formas: como "fim em si mesmo" ou como um "meio". O conteúdo escolar trabalhado como um fim em si mesmo advém de uma abordagem na qual o mais importante de todo processo educativo é o próprio conteúdo. O conteúdo escolar trabalhado como um meio pressupõe que o conteúdo a ser trabalhado deve estal 101 a serviço "como pano de fundo" de um "para quê" e "como" trabalhar.

A partir da análise dos planejamentos foi possível perceber que os temas e conteúdos que surgiram foram variados, porém a temática relacionada à alimentação saudável apareceu em 3 deles. A maioria dos planejamentos coletados (quatro) parte de uma abordagem sociointeracionista e (um) parte de uma abordagem tradicional. Em relação à 
orientação metodológica, quatro seguem a estrutura de um planejamento elementar, apresentando objetivos, justificativa, metodologia e conteúdos ou temas, enquanto apenas um deles procura partir de uma problematização inicial com questões sobre o tema a ser trabalhado que suscitem um debate sobre o assunto para depois seguirem nas etapas de organização e aplicação do conhecimento estudado, caracterizada como um projeto de ensino.

Alguns dos planejamentos tratam assuntos de forma ampla, com muito pouco detalhamento e isso pode dificultar sua realização, perdendo-se o verdadeiro sentido da ação de planejar, pois pode vir a ser um mero procedimento burocrático com escassa possibilidade de ser implementado na prática de sala de aula.

Apenas um planejamento previu possíveis ações alternativas, caso a implementação de algumas das atividades planejadas não pudessem ser postas em prática, por falta de interesse dos alunos no assunto a ser tratado.

Pode-se observar que em um dos planejamentos o professor assume a função de especialista enquanto em quatro dos planejamentos os professores assumem a função do professor mediador. As técnicas que mais apareceram nos planejamentos foram: as técnicas vinculadas a situações reais e técnicas de dinâmicas de grupo, uso de atividades presentes no objeto de aprendizagem "Nós no mundo" como já era esperado.

Observou-se que na maioria dos planejamentos, o uso do objeto de aprendizagem "Nós no mundo", propiciou um trabalho a partir do viés da mediação pedagógica, assim como se verificou que as estratégias pedagógicas planejadas pelos professores estavam relacionadas com a perspectiva teórica que fundamentava o objeto de aprendizagem utilizado embora em maior ou menor grau.

\section{Considerações finais}

O estudo realizado enfatizou a importância da construção de planejamentos que contenham referencial teórico, no qual o professor explicite o que pretende realizar, com que intenção e que estratégias pedagógicas podem auxiliá-lo a atingir os objetivos propostos. A proposta foi deslocar o sentido do planejamento, percebido ao vivenciá-lo como instrumento de organização de sua prática.

A perspectiva teórica do objeto de aprendizagem "Nós no mundo" e a proposta teórica do curso influenciaram os planejamentos dos professores, os quais reconfiguraram o seu fazer docente, readequando a sua prática.

Os professores pesquisados evidenciaram que o mais importante não é um planejamento fechado e completo, mas um plano com intencionalidades embasadas teoricamente para que o trabalho seja significativo e prazeroso, aprendendo alunos e professores a partir de suas interações.

A pesquisa ratificou que o planejamento não dá conta de toda a antecipação possível e não mostra tudo o que os professores pensam, mas é um importante instrumento para levar à prática aquilo que se pensa, dando direção ao trabalho pedagógico.

\section{Referências Bibliográficas}


IEEE Learning Tecnology Standard Committee (LTSC). (2005) In: WG12 Learning Object Metadata. Disponível em <http://ltsc.ieee.org/wg12> Acesso em 10/01/2006.

IEEE. Draft Standard for Learning Object Metadata, 15 de julho de 2002. Disponível em: http://ltsc.ieee.org/wg12/files/LOM_1484_12_1_v1_Final_Draft.pdf, acessado em maio de 2005.

MANATA, Dora Vianna. Planejamento docente, questão didática: "tenho tudo planejado na cabeça". In: Revista de educação AEC. Brasília, DF Vol. 33, n. 132 (jul./set. 2004).

MORAN, José Manuel; MASETTO, Marcos T.; BEHRENS, Marilda Aparecida. Novas Tecnologias e mediação pedagógica. São Paulo: Papirus, 2000.

RODRIGUES, Maria Bernadette Castro. Planejamento: desamarrando nós, atando o fazer pedagógico. In: Reconstrução curricular na escola democrática e popular: desafio para rede pública estadual no município de Porto Alegre. Porto Alegre: UFRGS. Núcleo de Integração Universidade \& Escola; Secretaria Estadual de Educação. Departamento de Coordenação das Regionais, 2002.

SECRETARIA DA EDUCAÇÃO. (1999) Parâmetros Curriculares Nacionais Ensino Fundamental, Brasília, MEC/SEF, 1999.

SOSTERIC, Nike; HESEMEIER, Susan. (2002) "When is a Learning Object not an Object: a first step towards a theory of learning objects". In: Internacional Review of Research in Open and Distance Learning. Disponível em $<$ http://www.irrodl.org/content/v3.2/soc-hes.html>. Acesso em 10/01/2006. 